\title{
The Theory and Practice of EDA Curriculum: a Preliminary Exploration of the Blending Teaching Model
}

\author{
Li Ce \\ School of New Energy, \\ College of Electrical and Information Engineering \\ Lanzhou University of Technology \\ Lanzhou, China \\ e-mail: christ.cli@foxmail.com
}

\author{
Zhang Xiu \\ School of New Energy \\ Lanzhou University of Technology \\ Lanzhou, China
}

\author{
$\mathrm{Li} \mathrm{Yu}$ \\ College of Electrical and Information Engineering \\ Lanzhou University of Technology \\ Lanzhou, China
}

\begin{abstract}
In the information age, the rapid development of new economy urgently needs the support of new engineering talents. The traditional classroom is boring. However, the theory and practice are often separate in two different places. And it makes college students lack of motivation and sense of achievement. For the above problem, author tried a kind of teaching mode that integration of classroom and laboratory, and theory teaching and practical aspects are synchronous with "EDA technology" which is undergraduate course of electrical engineering and automation. While break through the space constraints, author add many practical training methods in teaching such as inspiration, questioning, suspect, development, discussion. Students will not be boring with theory and equipment any more. And make them learn the course energetically, as well as give top priority to expand and achieve their own ideas. The teaching practice shows that this model effectively transforms students' passive learning into active learning, and effectively transforms the traditional classroom into all-round blending teaching with various flexible teaching methods. The teaching effect is well.
\end{abstract}

Keywords- Traditional classroom; Mixed teaching; EDA; Teaching mode

\section{INTRODUCTION}

With the advent of the information revolution era, the number of knowledge-based and technology-intensive industries has increased, and the demand for talent from the society has also shown a character of diversified. The information age, especially the mobile Internet era, is creating a completely different way of obtaining knowledge. Our memory seems increasingly dependent on the Internet, often referred to as "Internet dependence." Nowadays, college students, homework, or theses mostly rely on the Internet for information. They are indeed convenient and do not need to collect data and materials as hard as they used to. They took the initiative to think about it. This change has put forward some new requirements on higher education and created some new troubles. We must face up to and adapt to this change and set up an educational method in the information age. A person who does not have the ability to think independently and research will eventually be replaced by an artificial intelligence robot. The traditional classroom is boring because the theory and practice are often separate in two different places, and it makes college students lack of motivation and sense of achievement. For knowledge-based teaching, while strengthening knowledge, it has lost the concern for the existence and development of human beings fundamentally, and it is difficult to adapt to the current characteristics of student learning. How to find a teaching model which can teach classical theory and practice? How to find students' points of interest to transform passive learning to active learning? How do you find a way to immediately put what you have learned into action (what you see is what you get), so that students can initiative to like a kind of knowledge or technology in the sense of ongoing accomplishment? This is a question worth considering and urgent solution

The course of "EDA technology" taught by the author is obligatory course of electrical professional. It is a digital circuit system design by computer-assisted and FPGA development course [1]. The theory and the actual of this course are combinate very close. It require students not only need to understand the basic principles of FPGA / CPLD devices, and SOPC online programmable technology. At the same time, require students make the function to be coded, hardware to be software. To make a large-scale integrated circuit devices has a certain function finally. The course often separates in theoretical study and practical study because of the number of students and laboratory equipment, and it will limit creative thinking and training of students. This article will take this course as an example, trying to find 
a suitable new mode of teaching which integrates theory and practice, teaching and discussing, project and content.

\section{DEVELOPMENT TREND OF TEACHING MODE}

In order to combine the courses and think more reasonable teaching mode, we may wish to find solutions in the development trend of teaching mode. In general, different teaching theories, teaching objectives, teaching strategies and arrangements for the activities of teachers and students constitute a different teaching model. Design teaching mode should be based on the nature of the curriculum and the actual situation of teachers and students, and a good teaching model is conducive to students to actively accept and think[2]. With the development of society, the teaching mode in higher education teaching mainly has the following tendencies:

\section{A. From a single teaching methods to diversify teaching methods}

The traditional teaching is "Speak-Listen-Read-MemoryPractice". The characteristic is teachers instill knowledge and students accept knowledge mechanically[3]. The text in the book is almost identical with teachers' speak and the answers from students are also identical with teachers' teaching or textbook. Students learn knowledge mechanically. This teaching mode has been difficult to adapt information technology process in the age of big data. Thus with PPT, video data, 3D animation, and other teaching resources to emerge, breaking the traditional form of knowledge instillation. Modern classrooms also hope to become more colorful, so that students can learn more knowledge and discussion doubts[4-6]. However, the increasing amount of information in the classroom undoubtedly become one of the important factors that restrict the interaction of various modes. How to establish a full range of online and offline EDA technology course teaching mode? Only rely on theoretical teaching is hard to train the ability of students.

\section{B. Development from teacher-centered to student- centered}

The traditional teaching mode is elaborating about the teacher how to teach, but ignoring the students how to learn. People realize that students are the main body of learning, thus starting the study of teaching mode based on "Learning" since "anti-traditional" teaching mode proposed by Duwey. The development trend of modern teaching mode is to attach importance to the subjectivity and participation of students in teaching activities. The teaching model designed by this method of "teaching" and "learning" is reasonable. How to mobilize the enthusiasm of students and make them participate teaching actively. How to change the sense of gain of students into the initiative of learning has become the most important task in the teaching mode of this course.

\section{Development teaching model from island-type to expand-type}

The traditional teaching mode is usually taught their own courses but not pay attention to the establishment of a complete system of knowledge of students. All courses are out of line. Students only know what but don't know why. Students just care the task of solving, rather than the link between the system modules. The modern teaching model is more based on the project and result to inspire students to think about how to solve the problems[7-9]. Find solution in theory and practice experience. In this way, it is easier to establish the links between the various courses to make students not only know what, but also why. Only students who cultivate this mode of education may have more ability to innovate.

Throughout the development trend of teaching modes and the actual teaching of "EDA technology", we give the following solutions.

\section{THE PROPOSED BLENDING TEACHING MODE}

The course of "EDA Technology" reflects the rapid development of electronic information and chip integrated manufacturing and has a strong sense of the times. The modern electronic technology reflects the advanced, systematic, comprehensive and practical. At the same time, the course is still an important part of the link with many course such as "digital electronic technology" and "microcomputer principle and interface technology". Understanding the theoretical and practical knowledge in this course will help students to understand the combinational logic circuits, timing logic circuits, and state machines in "Digital Electronics" and timing, memory, and LED digital tube dynamic scanning principle in "Microcomputer Principle and Interface Technology" The course will also help students design their own electronic products that have functional and innovative. So we organize 40 students from electrical engineering and automation professional to have "EDA Technology". Our lab is shown in Figure 1. The experiment box used in this course is shown in Figure 2

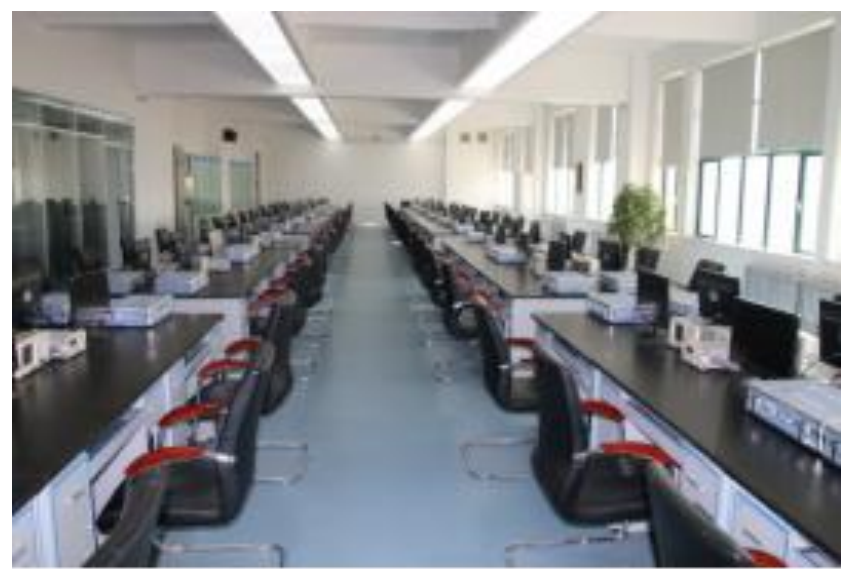

Figure 1. The environment of blending teaching classroom 


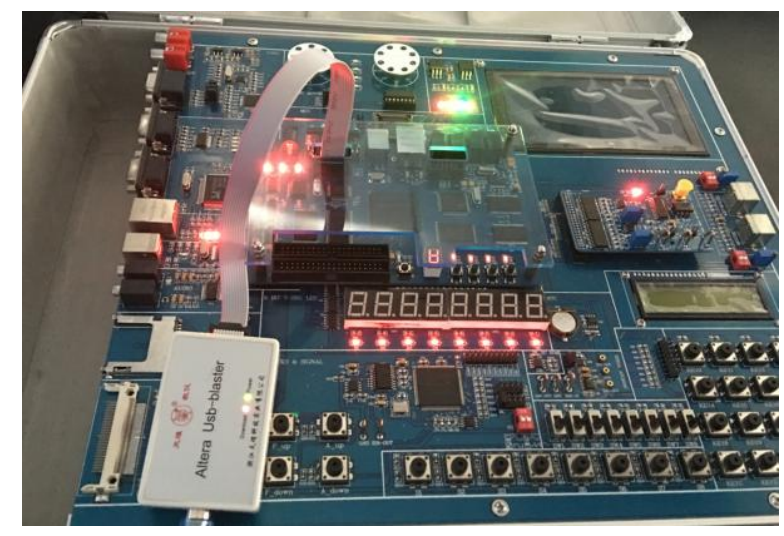

Figure 2. The EDA (SOPC / FPGA) experimental box

\section{A. The proposed model of teaching process}

Firstly, integrating the theoretical classroom and laboratory. Teachers lecture in the laboratory and use blackboard and PPT, and every student has one EDA (SOPC / FPGA) experimental box and connect it to PC. It will shorten the distance between theory and practice. Teacher presents and students operate at the same time, and encounter problems immediately resolved. With each point of knowledge reflected in practice, students get a sense of gain.

Secondly, during teaching courses, teachers pre-designed a number of items, which are students can complete it after the design and practice of the course. In this way, according to the different modules of the project in course, guide students to achieve the function of some modules, so that students will get more sense of accomplishment. And it also overcomes the scarcity that Chinese students are afraid to practice. For example, before teaching LED digital tube dynamic display, teacher tells students the knowledge in their project. While students understand and finish their work, they can achieve the instructions of the watch, welcome words, and other custom display. For this display result, to use inspiration, design, questioning, development, discussion and other forms to guide students to further thinking. When students practice by themselves, they can take the initiative to learn the knowledge, and know the learning expansion moreover. Which further promotes the students' learning initiative.

Finally, the initiative of students is improved, and there will be more questions in self-learning. Therefore, we also need to use internet and chatting tools to set up groups to answer questions in real time and even provide more knowledge links to guide students identify problems, analyze problems and solve problems. At the same time, in order to mobilize the students to combine the practice and theory, we will be set the scheduled completion of the project as the basis for the assessment of their course, and it will be $60 \%$ of the total score.

\section{B. The distribution of hours and the form of teaching}

Although this paper discusses a blending of theoretical and practical for teaching, the content of a course is also differentiated. Some of the contents of the course is theoretical, it is suitable for narration and discussion; some content is practical, it is suitable for hands-on experiment; and some content is comprehensive, it is suitable for discussion while talking about exercises. In short, in order to mobilize students' interest in learning, when setting the mixed mode, we should pay full attention to the content of each course and design more teaching methods for students to learn. Table 1 shows the teaching methods adopted by the author in teaching "EDA Technology" [10], which is for reference only.

TABLE I. "EDA TECHNOLOGY" COURSE TEACHING IN EACH PART OF THE BLENDING TEACHING

\begin{tabular}{|l|c|c|}
\hline \multicolumn{3}{|c|}{ EDA Technology } \\
\hline \multicolumn{1}{|c|}{ Chapter } & Hours & Type $^{*}$ \\
\hline Introduction & 2 & $\mathrm{~T}$ \\
\hline $\begin{array}{l}\text { VHDL program structure and } \\
\text { data objects }\end{array}$ & $2+2$ & $\mathrm{~T}+\mathrm{P}$ \\
\hline $\begin{array}{l}\text { VHDL data types and sequence } \\
\text { statements Simulation and }\end{array}$ & $2+2$ & $\mathrm{~T}+\mathrm{P}$ \\
\hline $\begin{array}{l}\text { Timing } \\
\text { Hardware Implementation }\end{array}$ & 6 & $\mathrm{~B}$ \\
\hline $\begin{array}{l}\text { VHDL parallel statement } \\
\text { LPM macro module application }\end{array}$ & 6 & $\mathrm{~B}$ \\
\hline $\begin{array}{l}\text { Advanced of VHDL design } \\
\text { Design and Application of } \\
\text { VHDL State Machine }\end{array}$ & 8 & $\mathrm{~T}$ \\
\hline $\begin{array}{l}\text { Project Design Practice } \\
\text { T- Theory teaching, P- practical teaching, B-Blending teaching }\end{array}$ \\
\hline
\end{tabular}

The proposed teaching model of "EDA technology" which through the integration of space and the combination of online and offline teaching. Students not only can quickly grasp the theoretical knowledge, but also can contact the practice process. And students will active learning in solving project problems. In this way, teacher shorten the distance between theory and practice, and give students motivation to learn as well as give the confidence and ability to take the initiative to solve the problem. The teaching mode practice data show that compared with the traditional and separate teaching mode, $95.8 \%$ students who are anonymous counted, interested in the proposed teaching model. The teaching feedback chart shown in Figure 3. 


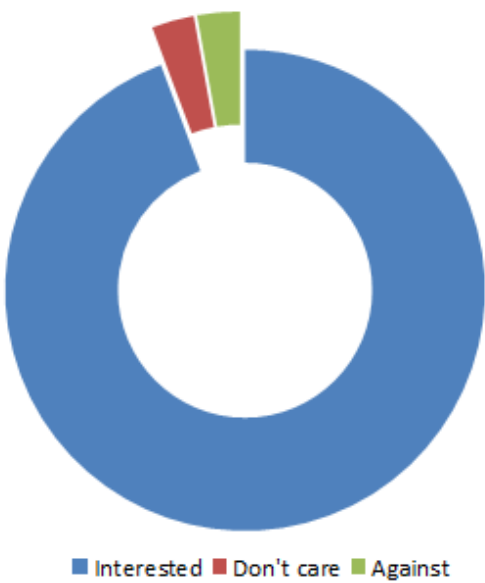

Figure 3. The charts of teaching feedback statistics

\section{CONCLUSION}

According to the nature of "EDA Technology" course and the situation of students in the class, this paper tries a blending teaching mode that integrates the theoretical teaching and practical teaching. And supplemented by online and offline teaching to get good teaching effect. In this paper, teacher and students contact and communicate in practical environment and practical results, so that students can be taught with their aptitude. As well as, the redundant teaching content produced of theory and practice will be reduced to a minimum, and the teaching efficiency will be improved, and the students will have more reward. We hope this teaching model will just be a special case of teaching to attract more peers in the education to work with students and create more splendid teaching models for their future.

\section{ACKNOWLEDGMENT}

This project has been funded by Lanzhou University of Technology Higher Education Research Project (2016-2017)

\section{REFERENCES}

[1] TIAN, J. Y., \& XIA, L. Y. (2005). Teaching Practice of EDA-Based Electronic Technology. Theory and Practice of Education, 12, 022.

[2] Edström, K., \& Kolmos, A.(2014). PBL and CDIO: complementary models for engineering education development. European Journal of Engineering Education, 39(5), 539-555.

[3] Chang, C. Y. (2001). Comparing the impacts of a problem-based computer-assisted instruction and the direct-interactive teaching method on student science achievement. Journal of Science Education and Technology, 10(2), 147-153.

[4] Kolmos, A., \& de Graaff, E. (2014). Problem-based and project-based learning in engineering education. Cambridge handbook of engineering education research, 141-161.

[5] Edström, K., \& Kolmos, A. (2012). Comparing two approaches for engineering education development: PBL and CDIO. In 2012 International CDIO Conference.

[6] John Hamilton, SingWhat Tee. (2013) Blended teaching and learning: a two-way systems approach. Higher Education Research \& Development 32(5): 748-764.

[7] Dabner, N., Davis, N., \& Zaka, P. (2012). Authentic project-based design of professional development for teachers studying online and blended teaching. Contemporary issues in technology and teacher education, 12(1), 71-114.

[8] Al-Otaibi, W. H. (2017). The Effectiveness of Blackboard-Based Blended Teaching in the Development of Academic Achievement, Study Skills and Self-Confidence among Students of Princess Nourah bint Abdulrahman University. International Education Studies, 10(11), 100 .

[9] Cheung, W. S., \& Hew, K. F. (2012, June). Our journey from face-toface to blended learning approach: Important lessons learned. In International Conference on e-Learning(p.27). Academic Conferences International Limited.

[10] Pan Song, Huang Jiye. (2014) EDA Technology and VHDL(Fourth edition). Tsinghua University Press. 